\title{
Effects of Persistent Allergic Rhinitis on Spirometric Parameters
}

\section{Majid Jafari*}

Allergy Research Center, Ghaem Hospital, Mashhad, Iran

*Corresponding author: Majid Jafari, Allergy Research Center, Ghaem Hospital, Mashhad, Iran, Tel: +98(513) 8012827, +98(912)2422776; E-mail: jafari.md.ped@Gmail.com

Received date: September 15, 2016; Accepted date: October 09, 2016; Published date: October 19, 2016

Copyright: (c) 2016 Jafari M. This is an open-access article distributed under the terms of the Creative Commons Attribution License, which permits unrestricted use, distribution, and reproduction in any medium, provided the original author and source are credited.

\begin{abstract}
Background: Allergic rhinitis (AR) is an inflammatory process due to allergens. The relation between AR and inflammation of lower airways is documented. However, AR is considered as the strong risk factor for the onset of asthma in adults.

Methods: This prospective cross sectional study carried out on 126 patients with perennial allergic rhinitis (PAR). Clinical examination, skin prick test and spirometry maneuver were performed in all patients.

Results: Our results showed that there is a significant difference between forced expiratory flow at $25 \%$ and $75 \%$ of the pulmonary volume (FEF 25.75). $<80 \%$ of the predicted for PAR $(P=0.003)$. There were no significant differences among patients with forced vital capacity (FVC) $<80 \%$ of predicted and forced expiratory volume in the first second( FEV1 $)<80 \%$ of the predicted, for PAR respectively $(P>0.05, P=0.08)$. Furthermore, in patients who were sensitive to indoor allergens, FEF25-75<80\% of the predicted was more impaired $(P=0.003)$. There was a negative correlation between FEF25-75 and the duration of disease $(r=-0.13)$.
\end{abstract}

Conclusion: This study highlights some risk factors such as the duration of PAR, age, indoor allergens and FEF25-75 as a marker of early bronchial involvement in patients with moderate-to severe and PAR alone.

Keywords: Allergic Rhinitis; Spirometry; Allergens; Asthma

\section{Introduction}

Allergic rhinitis (AR) is the inflammation of nasal airways due to irritation of mucosa by allergens such as pollens [1]. Association of AR with inflammation of lower airways has been documented and both conditions are theorized to be originated by a single inflammatory process that is supported by epidemiologic, histologic, physiologic and immunopathologic findings [2-4]. Approximately $40 \%$ of patients with chronic rhinitis have asthma and $80 \%$ of asthmatic patients suffer from persistent nasal symptoms [5]. Some studies recommend that patients with asthma should be appropriately evaluated for allergic rhinitis; the combined strategy should be used to treat the upper and lower airway diseases [6].

There is increasing information on the effects of small airways in the pathogenesis of asthma. There is not any direct parameters capable of assessing small airways, so forced expiratory flow (FEF) at the $25 \%$ and $75 \%$ of the pulmonary volume (FEF 25-75) in spirometry maneuver might be a more sensitive indicator of obstruction in small airways than forced expiratory volume in the first second (FEV1) $[7,8]$. Both FEV1 and mainly FEF25-75 are impaired in patients with AR and show nasal symptoms alone [7-9]. The FEF25-75 has been evidenced to be a reliable marker of early bronchial impairment in AR patients [10]. It has been reported that sensitization to indoor allergens is significantly associated with some of spirometric parameters significantly [11].

According to our literature review, there is little data on concomitant effects of $\mathrm{AR}$ in spirometric parameters. So, here we intended to investigate the possible effects of $A R$ and some risk factors such as duration of $\mathrm{AR}$, age, sex and allergens on spirometric parameters to cover current gap in the field. Furthermore we have also addressed frequency of allergens among AR patients who referred to us in our catastrophic area.

\section{Methods}

In this perspective cross sectional study, 126 patients with perennial allergic rhinitis (PAR) were recruited after approval of work by local ethics committee in Mashhad University of Medical Sciences (Approval letter number: 910801). All of the patients have been referred to the allergy clinic, Ghaem Hospital between Mar-Oct 2013. At the beginning of the study, a detailed clinical history was taken and a complete physical examination was performed. The patients were included in the study on the basis of a clinical history of persistent AR and presence of moderate-to-severe nasal symptoms according to the protocol of Allergic Rhinitis and its Impact on Asthma (ARIA) [12]. After including participants in the study, the other rhinitis causes were ruled out. We excluded all patients with asthma symptoms (cough, wheezing, dyspnea and shortness of breath), acute or chronic upper respiratory infections, anatomical nasal disorders (i.e. nasal polyps, septum deviation, etc.), smoking, previous or current specific immunotherapy and the use of nasal or oral corticosteroids, vasoconstrictors and anti-leukotrienes during the previous four weeks. All patients were treated with antihistamine drugs on demand. The diagnosis of our study participants was made on the basis of a history of nasal symptoms, clinical examination and positive skin prick test (SPT) according to validated criteria [10]. After describing the research procedure, volunteers singed the informed consent form and entered 
Page 2 of 5

the study. We performed SPT and spirometry maneuver for all patients under survey.

The SPT was carried out according to the instructions of the European Academy of Allergy and Clinical Immunology [10]. The panel of allergens included of outdoor allergens (Pigweed, Salsola kali and Ash), indoor allergens (Cat, Cockroach, Aspergillus, Penicillinium, Cladosporium, Alternaria and house dust mites including Dermatophagoides Farinae and Pteronyssinus (Stallergenes, Milan, Italy). The spirometry maneuver was done by spirometer (Spiro LABIII, Roma, Italy) according to the international guidelines and instruction of the manufacturer [13]. To evaluate the role of perennial allergic rhinitis on spirometric parameters (FEF25.75, forced vital capacity (FVC), and FEV1) were assessed. The interval reference value for current spirometric parameters was considered between $75-150 \%$ of predicted. To establish patients with susceptibility to asthma, we categorized patients under survey to two groups; patients with spirometric parameters $\geq 80 \%$ and spirometric parameters $\leq 80 \%$ of predicted.

SPSS for Windows, version 16 (SPSS Inc., Chicago, IL, USA) was used in all statistical procedures. Data were expressed as mean \pm SD. The normality of data was checked by Kolmogorov-Smirnov's test. Differences in proportions were judged by $\chi^{2}$ test. Then spirometric findings were analyzed by independent two-tailed t-test or mannWhitney test. P-valve $<0.05$ was considered as statistically significant.

\section{Results}

One hundred and twenty six patients (54 males and 72 females) with the BMI $(24.04 \pm 4.79)$ were included in this study. Their mean age was 28.80 years (SD: 11.37) with a minimum age of 9 and a maximum of 72 years. Demographic characteristics including gender, age and the duration of rhinitis were reported in Table 1. Among our study participants, 74 ones $(58.3 \%)$ had positive family history of rhinitis. The duration of disease was $6.84 \pm 0.65$ years. Patients were studied on the basis of their spirometric parameters (FVC, FEV1 and FEF25-75); there were $22(23.01 \%)$ patients with $\mathrm{FVC}<80 \%$ of predicted, $18(13.49 \%)$ with FEV1 $<80 \%$ of predicted and $39(30.95 \%)$ with FEF $25-75<80 \%$ of predicted. There was no difference between gender of the patients with FEV1, FEF25-75 or with FVC marker. Rhinitis duration was significantly higher in patients with impaired spirometric parameters. This result was confirmed by an evident correlation between FEF 25.75 values and rhinitis duration $(r=0.13)$ (Figure 1A) and between FEF25-75 values and age of the patients $(\mathrm{r}=0.10)$ (Figure 1B).

\begin{tabular}{|l|l|l|l|l|l|l|l|l|l|}
\hline & \multicolumn{3}{|l|}{ FEV1 } & \multicolumn{2}{l|}{ FEF25.75 } & \multicolumn{2}{l|}{ FVC } \\
\hline Variable & $>80(n=109)$ & $<80(n=17)$ & $P$ & $>80(n=87)$ & $<80(n=39)$ & $P$ & $>80(n=114)$ & $<80(n=22)$ & $P$ \\
\hline Gender: female & $59(46.82)$ & $13(10.31)$ & 0.6 & $47(37.30)$ & $25(19.84)$ & 0.19 & $60(47.61)$ & $12(9.52)$ & 0.48 \\
\hline Age; years & $28.75 \pm 10.69$ & $29.17 \pm 15.43$ & 0.001 & $27.97 \pm 10.79$ & $30.66 \pm 12.51$ & 0.012 & $26.50 \pm 12.12$ & $29.80 \pm 11.37$ & 0.009 \\
\hline Duration; years & $6.55 \pm 0.62$ & $8.64 \pm 0.75$ & 0.012 & $6.26 \pm 0.59$ & $8.12 \pm 0.75$ & 0.01 & $6.37 \pm 0.58$ & $9.04 \pm 0.87$ & 0.024 \\
\hline
\end{tabular}

Table 1: Demographic and clinical parameters of the patients with allergic rhinitis who divided into two groups according to their spirometric findings $(\mathrm{N}=126)$. Data in the parenthesis shows the percentages of studied patients. forced vital capacity=FVC, forced expiratory flow=FEF.

The results showed that the patients with impaired spirometric parameters in FEF25-75 markers (less than 80\%) were in middle age period. Moreover, this showed an inversely correlation with age $(\mathrm{r}=0.10)$ (Figure 1B).

This survey showed that with increasing duration of PAR, more patients had FEF25-75 $<80 \%$ of predicted and there was direct correlation $(\mathrm{r}=0.13)$ (Figure $1 \mathrm{~A})$.

About the total nasal score (TNS) and symptoms severity, the most common TNS symptom was sneezing in 124 (98.41\%) individuals and the less common symptom was smelling disorders in 76 (60.31\%) patients. Besides, the most severe symptoms were runny nose (79) and sneezing (76), while smelling disorders (9) had the least rank (Figure 2).

The prevalence of sensitivity to indoor and outdoor allergens and mixed allergens were 16 (12.69\%), 75 (58.73\%) and 35 (28.57\%) of studied individuals respectively. The frequency of allergen sensitivity has been presented in Table 2, which showed that among participants, allergy to house dust mites including Dermatophagoides farinae and Pteronyssinus and from indoor allergens, Salsola kali and ash from outdoor allergens had the highest frequencies.

The description of sensitizations in the two groups of patients (with each of the three spirometric parameters $<80 \%$ of predicted) was presented in Table 3. Data analysis showed that there was significant result for relationship between FEF $25.75<80 \%$ of predicted and indoor allergens $(\mathrm{P}=0.003)$.

\begin{tabular}{|l|l|l|}
\hline \multirow{2}{*}{ Variable } & Species & Frequency (\%) \\
\hline \multirow{5}{*}{ House dust mite } & D. pteronyssinus & $17(13.5)$ \\
\cline { 2 - 3 } & D. farinae & $8(6.3)$ \\
\hline \multirow{3}{*}{ Fungi } & Alternaria & $7(5.6)$ \\
\cline { 2 - 3 } & Penicilinium & $2(1.6)$ \\
\cline { 2 - 3 } Cockroach & Aspergillus & $7(5.6)$ \\
\cline { 2 - 3 } & Clodosporium & $2(1.6)$ \\
\hline Cat & & $2(1.6)$ \\
\hline \multirow{2}{*}{ Tree } & & $1(0.8)$ \\
\hline \multirow{2}{*}{ Weed } & Ash & $53(42.1)$ \\
\hline
\end{tabular}

Table 2: The Frequency of allergen sensitivity among studied patients with allergic rhinitis in 200 at north-eastern Iran. 
Page 3 of 5

Furthermore the number of sensitive female (13) to indoor allergens was higher than male (4).

There was no significant difference among $\mathrm{FVC}<80 \%$ of predicted and FEV $1<80 \%$ of predicted for allergens.

A

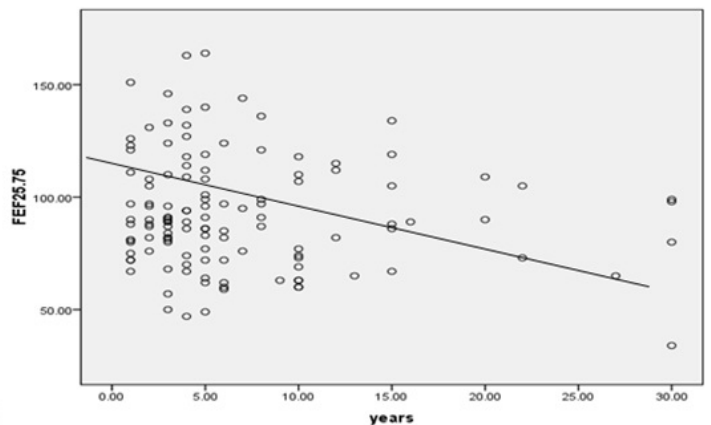

B

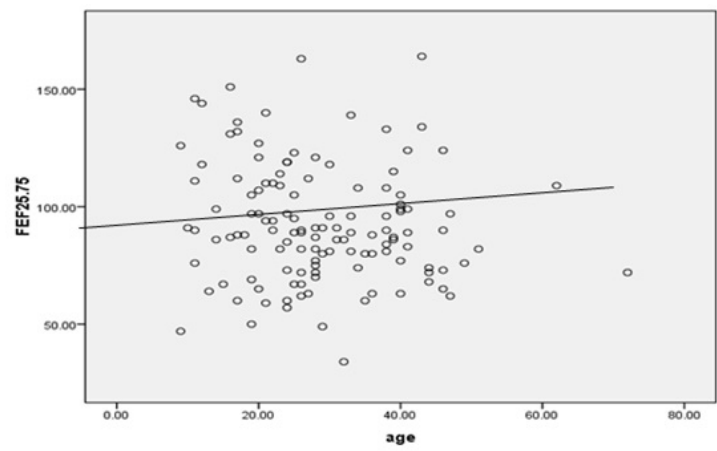

Figure 1: The relationship between FEF25-75\% and rhinitis duration in year (panel A) and relationship between FEF25-75\% and age in year (panel $\mathrm{B}$ ).

Patients with FEF25.75<80\% of predicted had the lowest frequency and had statistically significant difference with the patients who had positive reaction to indoor allergens (house dust mites) and had a greater percentage of the patients with positive reaction to outdoor allergens (grass, trees, weeds) and mixed allergens $(\mathrm{P}=0.003)$. Patients with impaired $\mathrm{FEV} 1<80 \%$, FEF $25.75<80 \%$ and $\mathrm{FVC}<80 \%$ of predicted had more positive reactions for outdoor allergens (Table 3 ).

\section{Discussion}

Allergic rhinitis and asthma should be considered as a single syndrome as the previous studies showed that AR is mostly associated with asthma [14-16]. The severe and moderate allergic rhinitis is considered as robust predictors for severe asthma [17]. In comparison with the patients with merely asthma, the patients with both asthma and concomitant allergic rhinitis recruit more medical surveillance and expenses that are estimated to be 2 fold. Therefore, evaluation of rhinitis symptoms would be done for amelioration of asthma $[18,19]$. This might be due to the lower resolution of airway obstruction [20-22]. The current study investigated the possible effects of perennial $\mathrm{AR}$ on impairment of spirometric parameters and its relation to sensitivity of the patients to various allergens as moderate-to-severe types.

The results showed that female gender with PAR may be more susceptible to impaired spirometry parameters. In comparison to pervious study [23], this survey only showed the relation between susceptibility of female patients with FEF $25.75<80 \%$ of predicted, while in contrast to Ciprandi et al. study we could not confirm relation between sex of the patients and $\mathrm{FEV} 1<80 \%$ \& $\mathrm{FVC}<80 \%$ of predicted [11]. Although in both studies the sex of the patients for different spirometric variables was not significant. It would be noted that in our community females spend most of their daytime in closed spaces including houses. Moreover, as most of the women are housekeepers, they spend more time in houses and are more prone to have continuous contact with indoor allergens. This may be a causative factor that makes women more susceptible.

Another relevant risk factor was rhinitis duration that may have impressive effect on impaired spirometric parameters. This result is confirmed by an evident correlation between FEF25-75<80\% of predicted and rhinitis duration. The duration of disease in recent survey was longer than previous studies [21-23].

Owing to evaluation of relation between age and spirometric parameter (FEF25-75) revealed that in contrast of the previous study [11], there is a significant correlation between FEF25-75<80\% of predicted. Hence, in the group of middle age patients, with increasing age less impaired spirometric values has been observed (Figure 1B).

\begin{tabular}{|l|l|l|l|l|l|l|}
\hline \multirow{2}{*}{ Allergen } & \multicolumn{2}{l|}{ FEF25.75\% of predicted } & \multicolumn{2}{l|}{ FVC \% of predicted } & \multicolumn{2}{l|}{ FEV1 \% of predicted } \\
\cline { 2 - 7 } & $<80(\mathrm{n}=39)$ & $>80(\mathrm{n}=87)$ & $<80(\mathrm{n}=22)$ & $>80(\mathrm{n}=114)$ & $<80(\mathrm{n}=18)$ & $>80(\mathrm{n}=108)$ \\
\hline Indoors & $9(7.1)$ & $7(5.55)$ & $2(1.58)$ & $14(11.11)$ & $4(3.17)$ & $12(9.52)$ \\
\hline Out doors & $15(11.90)$ & $60(47.61)$ & $12(9.52)$ & $63(50)$ & $6(4.76)$ & $69(54.76)$ \\
\hline Mixed & $15(11.90)$ & $20(15.87)$ & $8(6.34)$ & $27(21.42)$ & $8(5.55)$ & $27(42.85)$ \\
\hline P-value & 0.003 & 0.4 & & 0.08 & \\
\hline
\end{tabular}

Table 3: The cross tabulation of spirometric variables and Allergen types. Data in the parenthesis shows the percentage of studied patients on this variable. Forced vital capacity=FVC, forced expiratory flow=FEF. 
Page 4 of 5

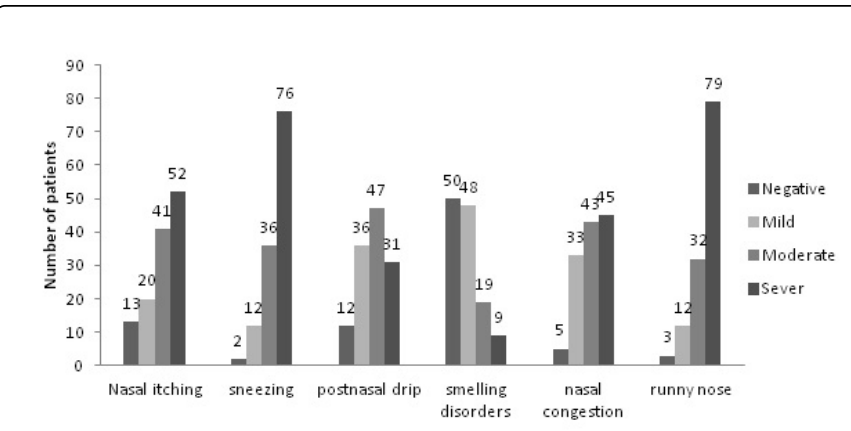

Figure 2: Total nasal score severity symptoms in studied participants with allergic rhinitis in 2013 at north-eastern Iran.

Besides, the number of sensitizations to indoor allergens and its effect on bronchial airflow limitation in AR, we found that presence of FEF $25.75<80 \%$ of predicted had the lowest number and statistically significant differences in the patients sensitive to outdoor and polysensitized allergens. However Ciprandi et al. found that indoor allergens (house dust mite) sensitization represents the most impressive risk factor as well as the presence of polysensitization with reduced values of both FEV1 and FVC [11]. Owing to sensivity to indoor allergens is important risk factor of bronchial impairment in rhinitis allergy. Moreover, exposure to indoor allergens cause minimal persistent inflammation that leads to the development of structural bronchial remodeling and this induces the persistence of inflammatory event and finally impairment of respiratory function.

Our findings emphasis that bronchial involvement may be frequent in AR, even in the absence of overt asthmatic symptoms. According to ARIA recommendation, each patient with allergic rhinitis has to be evaluated about both upper and lower airway diseases and in the case of illness should be supported appropriately.

One of the limitations of this study was the small sample size. This was due to the scarcity of the patients with moderate-to-severe and PAR alone and without asthmatic symptoms due to difficulty of large adequacy of patients with those characteristics.

This study highlights the close link between upper and lower airways and the role of some risk factors such as duration, age, sex and indoor sensitization. Besides it is appeared that FEF25-75 can be included as a marker of early bronchial involvement in patients suffering from isolated PAR. Furthermore, the other spirometric parameters may be impaired in AR, especially when allergen exposure persists (typically for indoor allergen) this issue confirms the concept that airway allergic inflammation and airflow impairment are closely associated as well as upper and lower airways.

These findings are in accordance with the previous studies that showed high percentage of the patients with AR show spirometric abnormalities, regarding to FEF $25-75<80 \%$ of predicted. Therefore our results highlight that a bronchial involvement is frequent in $A R$, despite overt asthmatic symptoms.

\section{Conclusion}

It seems from clinical point of view that for treatment of $A R$, it would be logical to considering the presence of some risk factors and involvement of lower respiratory system. It is suggested for future follow up studies to contemplate whether such high risk populations actually go on to develop asthma or not?

\section{References}

1. May JR, Smith PH (2009) Allergic Rhinitis. In: DiPiro JT, Talbert RL, Yee GC, Matzke G, Wells B, Posey LM. Pharmacotherapy: A Pathophysiologic Approach (7th ed.). New York: McGraw-Hill. pp. 1565-75.

2. Bousquet J, Khaltaev N, Cruz AA (2002) Allergic rhinitis and its impact on asthma. In collaboration with the World Health Organization. Executive summary of the workshop report. Geneva, Switzerland. Allergy 5: 841-855.

3. Simons FE (1999) Allergic rhinobronchitis: the asthma-allergic rhinitis link. J Allergy Clin Immunol 104: 534-540.

4. Bousquet J, Vignola AM, Demoly P (2003) Links between rhinitis and asthma. Allergy 58: 691-706.

5. Adkinson Jr, Bochner BS, Burks W, Busse WW, Holgate ST, et al. (2013) Middleton's allergy: principles and practice. Elsevier Health Sciences (8th ed.). N. Franklin Adkinson.

6. Canonica GW (2002) Introduction to nasal and pulmonary allergy cascade. Allergy 75: 8-12.

7. Bousquet J, Van Cauwenberge P, Khaltaev N, Aria Workshop Group, World Health Organization (2001) Allergic rhinitis and its impact on asthma. J Allergy Clin Immunol 108: S147-334.

8. Hamid Q, Song Y, Kotsimbos TC, Minshall E, Bai TR, et al. (1997) Inflammation of small airways in asthma. J Allergy Clin Immunol 100: 44-51.

9. Pellegrino R, Viegi G, Brusasco V, Crapo RO, Burgos F, et al. (2005) Interpretative strategies for lung function tests. Eur Respir J 26: 948-968.

10. Miller MR, Hankinson J, Brusasco V, Burgos F, Casaburi R, et al. (2005) Standardisation of spirometry. Eur Respir J 26: 319-338.

11. Ciprandi G, Cirillo I, Pistorio A (2008) Impact of allergic rhinitis on asthma: effects on spirometric parameters. Allergy 63: 255-260.

12. Brozek JL, Bousquet J, Baena-Cagnani CE, Bonini S, Canonica GW, et al. (2010) Allergic Rhinitis and its Impact on Asthma (ARIA) guidelines: 2010 revision. J Allergy Clin Immunol 126: 466-476.

13. Pellegrino R, Viegi G, Brusasco V, Crapo RO, Burgos F, et al. (2005) Interpretative strategies for lung function tests. Eur Respir J 26: 948-968.

14. Miller MR, Hankinson J, Brusasco V, Burgos F, Casaburi R, et al. (2005) Standardisation of spirometry. Eur Respir J 26: 319-338.

15. Simons FER (2003) What's in a name? The allergic rhinitis-asthma connection. Clin Exp All Rev 3: 9-17.

16. Ponte EV, Franco R, Nascimento HF, Souza-Machado A, Cunha S, et al. (2008) Lack of control of severe asthma is associated with co-existence of moderate-to-severe rhinitis. Allergy 63: 564-569.

17. Halpern MT, Schmier JK, Richner R, Guo C, Togias A (2004) Allergic rhinitis: a potential cause of increased asthma medication use, costs, and morbidity. J Asthma 41: 117-126.

18. Brandão HV, Cruz CS, Pinheiro $M C$, Costa EA, Guimarães $\mathrm{A}$, et al. (2009)Risk factors for ER visits due to asthma exacerbations in patients enrolled in a program for the control of asthma and allergie rhinitis in Feira de Santana, Brazil. J Brasileiro de Pneumologia 35: 1168-1173.

19. Pinto Pereira LM, Jackman J, Figaro N, Babootee N, Cudjoe G, et al. (2010) Health burden of co-morbid asthma and allergic rhinitis in West Indian children. Allergol Immunopathol (Madr) 38: 129-134.

20. Thomas M, Kocevar VS, Zhang Q, Yin DD, Price D (2005) Asthmarelated health care resource use among asthmatic children with and without concomitant allergic rhinitis. Pediatrics 115: 129-134.

21. Brandão HV, Cruz CM, Santos Ida S Jr, Ponte EV, Guimarães A, et al. (2009) Hospitalizations for asthma: impact of a program for the control of asthma and allergic rhinitis in Feira de Santana, Brazil. J Bras Pneumol 35: 723-729.

22. Zorc JJ, Chew A, Allen JL, Shaw K (2011) Factors associated with asthma control in a pediatric reference center. Revista Paulista de Pediatria 29: 591-598. 
Citation: Jafari M (2016) Effects of Persistent Allergic Rhinitis on Spirometric Parameters. J Allergy Ther 7: 242. doi:10.4172/2155-6121.1000242

Page 5 of 5

23. Sazonov Kocevar V, Thomas J, Jonsson L, Valovirta E, Kristensen F, et al. (2005) Association between allergic rhinitis and hospital resource use among asthmatic children in Norway. Allergy 60: 338-342. 